
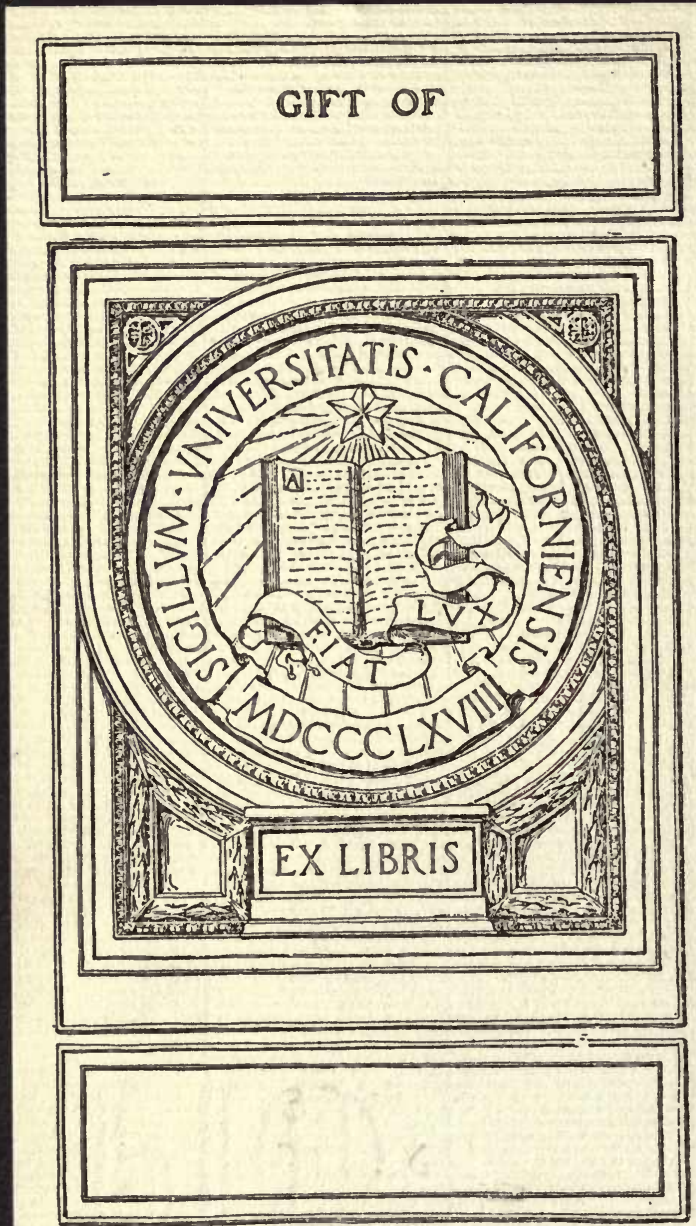

8061 ' 12 Nar 'IVd

- $\mathrm{N}$ 'วsnoed $\alpha \mathrm{S}$ sдатe 


$$
\operatorname{luN}_{28}^{\operatorname{crm}} 1.991
$$

\title{
The Evolution of the Scientific Investigator
}

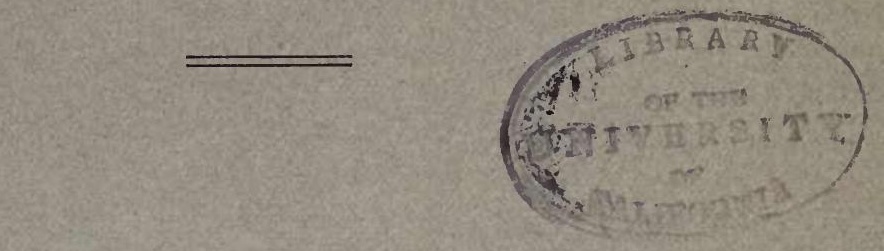

\section{OPENING ADDRESS}

AT THE

International Congress of Arts and Science

AT THE

\author{
Universal Exposition, St. Louis \\ September 19, 1904
}

$\begin{array}{ll}\text { By } & \\ \text { SIMON NEWCOMB }\end{array}$ 



\title{
The Evolution of the Scientific Investigator
}

\section{OPENING ADDRESS}

AT THE

International Congress of Arts and Science AT THE

Universal Exposition, St. Louis

September 19, 1904

\author{
By \\ SIMON NEWCOMB
}




$$
\cos _{1} n_{4}
$$

Gir's

$\because \because \therefore \quad \therefore \because \vdots \vdots \vdots \vdots \vdots \vdots 0$

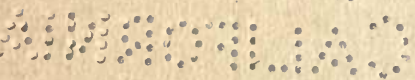




\section{THE EVOLUTION OF THE -SCIENTIFIC INVESTIGATOR.}

As we look at the assemblage gathered in this hall, comprising so many names of widest renown in every branch of learning-we might almost say in every field of human endeavor-the first inquiry suggested must be after the object of our meeting. The answer is that our purpose corresponds to the eminence of the assemblage. We aim at nothing less than a survey of the realm of knowledge, as comprehensive as is permitted by the limitations of time and space. The organizers of our congress have honored me with the charge of presenting such preliminary view of its field as may make clear the spirit of our undertaking.

Certain tendencies characteristic of the science of our day clearly suggest the direction of our thoughts most appropriate to the occasion. Among the strongest of these is one toward laying greater stress on questions of the beginning of things, and regarding a knowledge of the laws of development of any object of study as necessary to the understanding of its present form. It may be conceded that the principle here involved is as applicable in the broad field before us as in a special research into the properties of the minutest organism. It therefore seems meet that we should begin by inquiring what agency has brought about the remarkable development of science 
to which the world of today bears witness. This view is recognized in the plan of our proceedings by providing for each great department of knowledge a review of its progress during the century that has elapsed since the great event commemorated by the scenes outside this hall. But such reviews do not make up that general survey of science at large which is necessary to the development of our theme, and which must include the action of causes that had their origin long before our time. The movement which culminated in making the nineteenth century ever memorable in history is the outcome of a long series of causes, acting through many centuries, which are worthy of especial attention on such an occasion as this. In setting them forth we should avoid laying stress on those visible manifestations which, striking the eye of every beholder, are in no danger of being overlooked, and search rather for those agencies whose activities underlie the whole visible scene, but which are liable to be blotted out of sight by the very brilliancy of the results to which they have given rise. It is easy to draw attention to the wonderful qualities of the oak; but, from that very fact, it may be needful to point out that the real wonder lies concealed in the acorn from which it grew.

Our inquiry into the logical order of the causes which have made our civilization what it is today will be facilitated by bringing to mind certain elementary considerations -ideas so familiar that setting them forth may seem like citing a body of truisms-and yet so frequently overlooked, not only individually, but in their relation to each other, that the conclusion to 
which they lead may be lost to sight. One of these propositions is that psychical rather than material causes are those which we should regard as fundamental in directing the development of the social organism. The human intellect is the really active agent in every branch of endeavor-the primum mobite of civilization-and all those material manifestations to which our attention is so often directed are to be regarded as secondary to this first agency. If it be true that "in the world is nothing great but man; in man is nothing great but mind," then should the keynote of our discourse be the recognition of this first and greatest of powers.

Another well-known fact is that those applications of the forces of nature to the promotion of human welfare which have made our age what it is are of such comparatively recent origin that we need go back only a single century to antedate their most important features, and scarcely more than four centuries to find their beginning. It follows that the subject of our inquiry should be the commencement, not many centuries ago, of a certain new form of intellectual activity.

Having gained this point of view, our next inquiry will be into the nature of that activity and its relation to the stages of progress which preceded and followed its beginning. The superficial observer, who sees the oak but forgets the acorn, might tell us that the special qualities which have brought out such great results are expert scientific knowledge and rare ingenuity, directed to the application of the powers of steam and electricity. From this point of view the great inventors 
and the great captains of industry were the first agents in bringing about the modern era. But the more careful inquirer will see that the work of these men was possible only through a knowledge of the laws of nature, which had been gained by men whose work took precedence of theirs in logical order, and that success in invention has been measured by completeness in such knowledge. While giving all due honor to the great inventors, let us remember that the first place is that of the great investigators, whose forceful intellects opened the way to secrets previously hidden from men. Let it be an honor and not a reproach to these men that they were not actuated by the love of gain, and did not keep utilitarian ends in view in the pursuit of their researches. If it seems that in neglecting such ends they were leaving undone the most important part of their work, let us remember that nature turns a forbidding face to those who pay her court with the hope of gain, and is responsive only to those suitors whose love for her is pure and undefiled. Not only is the special genius required in the investigator not that generally best adapted to applying the discoveries which he makes, but the result of his having sordid ends in view would be to narrow the field of his efforts, and exercise a depressing effect upon his activities. The true man of science has no such expression in his vocabulary as "useful knowledge." His domain is as wide as nature itself, and he best fulfills his mission when he leaves to others the task of applying the knowledge he gives to the world.

We have here the explanation of the well-known fact that the functions of the investigator of the laws of 
nature, and of the inventor who applies these laws to utilitarian purposes, are rarely united in the same person. If the one conspicuous exception which the past century presents to this rule is not unique, we should probably have to go back to Watt to find another.

From this viewpoint it is clear that the primary agent in the movement which has elevated man to the masterful position he now occupies is the scientific investigator. $\mathrm{He}$ it is whose work has deprived plague and pestilence of their terrors, alleviated human suffering, girdled the earth with the electric wire, bound the continent with the iron way, and made neighbors of the most distant nations. As the first agent which has made possible this meeting of his representatives, let his evolution be this day our worthy theme. As we follow the evolution of an organism by studying the stages of its growth, so we have to show how the work of the scientific investigator is related to the ineffectual efforts of his predecessors.

In our time we think of the process of development in nature as one going continuously forward through the combination of the opposite processes of evolution and dissolution. The tendency of our thought has been in the direction of banishing cataclysms to the theological limbo, and viewing nature as a sleepless plodder, endowed with infinite patience, waiting through long ages for results. I do not contest the truth of the principle of continuity on which this view is based. But it fails to make known to us the whole truth. The building of a ship from the time that her keel is laid until she is making her way across the ocean is a slow and gradual process; yet there is a cataclysmic epoch 
opening up a new era in her history. It is the moment when, after lying for months or years a dead, inert, immovable mass, she is suddenly endowed with the power of motion, and, as if imbued with life, glides into the stream, eager to begin the career for which she was designed.

I think it is thus in the development of humanity. Long ages may pass during which a race, to all external observation, appears to be making no real progress. Additions may be made to learning, and the records of history may constantly grow, but there is nothing in its sphere of thought, or in the features of its life, that can be called essentially new. Yet, nature may have been all along slowly working in a way which evades our scrutiny until the result of her operations suddenly appears in a new and revolutionary movement, carrying the race to a higher plane of civilization.

It is not difficult to point out such epochs in human progress. The greatest of all, because it was the first, is one of which we find no record either in written or geological history. It was the epoch when our progenitors first took conscious thought of the morrow, first used the crude weapons which nature had placed within their reach to kill their prey, first built a fire to warm their bodies and cook their food. I love to fancy that there was some one first man, the Adam of evolution, who did all this, and who used the power thus acquired to show his fellows how they might profit by his example. When the members of the tribe or community which he gathered around him began to conceive of life as a whole-to include yesterday, to-day and to-morrow in the same mental grasp-to 
think how they might apply the gifts of nature to their own uses-a movement was begun which should ultimately lead to civilization.

Long indeed must have been the ages required for the development of this rudest primitive community into the civilization revealed to us by the most ancient tablets of Egypt and Assyria. After spoken language was developed, and after the rude representation of ideas by visible marks drawn to resemble them had long been practiced, some Cadmus must have invented an alphabet. When the use of written language was thus introduced, the word of command ceased to be confined to the range of the human voice, and it became possible for master minds to extend their influence as far as a written message could be carried. Then were communities gathered into provinces; provinces into kingdoms; kingdoms into the great empires of antiquity. Then arose a stage of civilization which we find pictured in the most ancient records-a stage in which men were governed by laws that were perhaps as wisely adapted to their conditions as our laws are to ours-in which the phenomena of nature were rudely observed, and striking occurrences in the earth or in the heavens recorded in the annals of the nation.

Vast was the progress of knowledge during the interval between these empires and the century in which modern science began. Yet, if I am right in making a distinction between the slow and regular steps of progress, each growing naturally out of that which preceded it, and the entrance of the mind at some fairly definite epoch into an entirely new sphere of activity, it would appear that there was only one 
such epoch during the entire interval. This was when abstract geometrical reasoning commenced, and astronomical observations aiming at precision were recorded, compared and discussed. Closely associated with it must have been the construction of the forms of logic. The radical difference between the demonstration of a theorem of geometry and the reasoning of everyday life which the masses of men must have practiced from the beginning, and which few even today ever get beyond, is so evident at a glance that I need not dwell upon it. The principal feature of this advance is that, by one of those antinomies of the human intellect of which examples are not wanting even in our own time, the development of abstract ideas preceded the concrete knowledge of natural phenomena. When we reflect that in the geometry of Euclid the science of space was brought to such logical perfection that even today its teachers are not agreed as to the practicability of any great improvement upon it, we cannot avoid the feeling that a very slight change in the direction of the intellectual activity of the Greeks would have led to the beginning of natural science. But it would seem that the very purity and perfection which was aimed at in their system of geometry stood in the way of any extension or application of its methods and spirit to the field of nature. One example of this is worthy of attention. In modern teaching the idea of magnitude as generated by motion is freely introduced. A line is described by a moving point; a plane by a moving line; a solid by a moving plane. It may, at first sight, seem singular that this conception finds no place in the Euclidian system. But we may regard the omission 
as a mark of logical purity and rigor. Had the real or supposed advantages of introducing motion into geometrical conceptions been suggested to Euclid, we may suppose him to have replied that the theorems of space are independent of time; that the idea of motion necessarily implies time, and that, in consequence, to avail ourselves of it would be to introduce an extraneous element into geometry.

It is quite possible that the contempt of the ancient philosophers for the practical application of their science, which has continued in some form to our own time, and which is not altogether unwholesome, was a powerful factor in the same direction. The result was that, in keeping geometry pure from ideas which did not belong to it, it failed to form what might otherwise have been the basis of physical science. Its founders missed the discovery that methods similar to those of geometric demonstration could be extended into other and wider fields than that of space. Thus not only the development of applied geometry but the reduction of other conceptions to a rigorous mathematical form was indefinitely postponed.

Astronomy is necessarily a science of observation pure and simple, in which experiment can have no place except as an auxiliary. The vague accounts of striking celestial phenomena handed down by the priests and astrologers of antiquity were followed in the time of the Greeks by observations having, in form at least, a rude approach to precision, though nothing like the degree of precision that the astronomer of today would reach with the naked eye, aided by such instruments as he could fashion from the tools at the command of the ancients. 
The rude observations commenced by the Babylonians were continued with gradually improving instruments-first by the Greeks and afterward by the Arabs-but the results failed to afford any insight into the true relation of the earth to the heavens. What was most remarkable in this failure is that, to take a first step forward which would have led on to success, no more was necessary than a course of abstract thinking vastly easier than that required for working out the problems of geometry. That space is infinite is an unexpressed axiom, tacitly assumed by Euclid and his successors. Combining this with the most elementary consideration of the properties of the triangle, it would be seen that a body of any given size could be placed at such a distance in space as to appear to us like a point. Hence a body as large as our earth, which was known to be a globe from the time that the ancient Phœnicians navigated the Mediterranean, if placed in the heavens at a sufficient distance, would look like a star. The obvious conclusion that the stars might be bodies like our globe, shining either by their own light or by that of the sun, would have been a first step to the understanding of the true system of the world.

There is historic evidence that this deduction did not wholly escape the Greek thinkers. It is true that the critical student will assign little weight to the current belief that the vague theory of Pythagoras-that fire was at the centre of all things-implies a conception of the heliocentric theory of the solar system. But the testimony of Archimedes, confused though it is in form, leaves no serious doubt that Aristarchus of Samos 
not only propounded the view that the earth revolves both on its own axis and around the sun, but that he correctly removed the great stumbling-block in the way of this theory by adding that the distance of the fixed stars was infinitely greater than the dimensions of the earth's orbit. Even the world of philosophy was not yet ready for this conception, and, so far from seeing the reasonableness of the explanation, we find Ptolemy arguing against the rotation of the earth on grounds which careful observations of the phenomena around him would have shown to be ill-founded.

Physical science, if we can apply that term to an unco-ordinated body of facts, was successfully cultivated from the earliest times. Something must have been known of the properties of metals, and the art of extracting them from their ores must have been practiced, from the time that coins and medals were first stamped. The properties of the most common compounds were discovered by alchemists in their vain search for the philosopher's stone, but no actual progress worthy of the name rewarded the practitioners of the black art.

Perhaps the first approach to a correct method was that of Archimedes, who by much thinking worked out the law of the lever, reached the conception of the centre of gravity, and demonstrated the first principles of hydrostatics. It is remarkable that he did not extend his researches into the phenomena of motion, whether spontaneous or produced by force. The stationary condition of the human intellect is most strikingly illustrated by the fact that not until the time of Leonardo was any substantial advance made on his 
discovery. To sum up in one sentence the most characteristic feature of ancient and medieval science, we see a notable contrast between the precision of thought implied in the construction and demonstration of geometrical theorems and the vague indefinite character of the ideas of natural phenomena generally, a contrast which did not disappear until the foundations of modern science began to be laid.

We should miss the most essential point of the difference between medieval and modern learning if we looked upon it as mainly a difference either in the precision or the amount of knowledge. The development of both of these qualities would, under any circumstances, have been slow and gradual, but sure. We can hardly suppose that any one generation, or even any one century, would have seen the complete substitution of exact for inexact ideas. Slowness of growth is as inevitable in the case of knowledge as in that of a growing organism. The most essential point of difference is one of those seemingly slight ones, the importance of which we are too apt to overlook. It was like the drop of blood in the wrong place, which some one has told us makes all the difference between a philosopher and a maniac. It was all the difference between a living tree and a dead one, between an inert mass and a growing organism. The transition of knowledge from the dead to the living form must, in any complete review of the subject, be looked upon as the really great event of modern times. Before this event the intellect was bound down by a scholasticism which regarded knowledge as a rounded whole, the parts of which were written in books and carried in the minds 
of learned men. The student was taught from the beginning of his work to look upon authority as the foundation of his beliefs. The older the authority the greater the weight it carried. So effective was this teaching that it seems never to have occurred to individual men that they had all the opportunities ever enjoyed by Aristotle of discovering truth, with the added advantage of all his knowledge to begin with. Advanced as was the development of formal logic, that practical logic was wanting which could see that the last of a series of authorities, every one of which rested on those which preceded it, could never form a surer foundation for any doctrine than that supplied by its original propounder.

The result of this view of knowledge was that, although during the fifteen centuries following the death of the geometer of Syracuse great universities were founded at which generations of professors expounded all the learning of their time, neither professor nor student ever suspected what latent possibilities of good were concealed in the most familiar operations of nature. Every one felt the wind blow, saw water boil and heard the thunder crash, but never thought of investigating the forces here at play. Up to the middle of the fifteenth century the most acute observer could scarcely have seen the dawn of a new era.

In view of this state of things it must be regarded as one of the most remarkable facts in evolutionary history that four or five men, whose mental constitution was either typical of the new order of things or who were powerful agents in bringing it about, were all 
born during the fifteenth century, four of them at least at so nearly the same time as to be contemporaries.

Leonardo da Vinci, whose artistic genius has charmed succeeding generations, was also the first practical engineer of his time, and the first man after Archimedes to make a substantial advance in developing the laws of motion. That the world was not prepared to make use of his scientific discoveries does not detract from the significance which must attach to the period of his birth.

Shortly after him was born the great navigator whose bold spirit was to make known a new world, thus giving to commercial enterprise that impetus which was so powerful an agent in bringing about a revolution in the thoughts of men.

The birth of Columbus was soon followed by that of Copernicus, the first after Aristarchus to demonstrate the true system of the world. In him more than in any of his contemporaries do we see the struggle between the old forms of thought and the new. It seems almost pathetic and is certainly most suggestive of the general view of knowledge taken at that time that, instead of claiming credit for bringing to light great truths before unknown, he made a labored attempt to show that, after all, there was nothing really new in his system, which he claimed to date from Pythagoras and Philolaus. In this connection it is curious that he makes no mention of Aristarchus, who I think will be regarded by conservative historians as his only demonstrated predecessor. To the hold of the older ideas upon his mind we must attribute the fact that in constructing his system he took great pains 
to make as little change as possible in ancient conceptions.

Luther, the greatest thought-stirrer of them all, practically of the same generation with Copernicus, Leonardo and Columbus, does not come in as a scientific investigator, but as the great loosener of chains which had so fettered the intellect of men that they dared not think otherwise than as the authorities thought.

Almost coeval with the advent of these intellects was the invention of printing with movable type. Gutenberg was born during the first decade of the century, and his associates and others credited with the invention not many years afterward. If we accept the principle on which I am basing my argument, that we should assign the first place to the birth of those psychic agencies which started men on new lines of thought, then surely was the fifteenth the wonderful century.

Let us not forget that, in assigning the actors then born to their places, we are not narrating history, but studying a special phase of evolution. It matters not for us that no university invited Leonardo to its halls, and that his science was valued by his contemporaries only as an adjunct to the art of engineering. The great fact still is that he was the first of mankind to propound laws of motion. It is not for anything in Luther's doctrines that he finds a place in our scheme. No matter for us whether they were sound or not. What he did toward the evolution of the scientific investigator was to show by his example that a man might question the best-established and most venerable authority and still live-still preserve his intellectual 
integrity - still command a hearing from nations and their rulers. It matters not for us whether Columbus ever knew that he had discovered a new continent. His work was to teach that neither hydra, chimera nor abyss-neither divine injunction nor infernal machination-was in the way of men visiting every part of the globe, and that the problem of conquering the world reduced itself to one of sails and rigging, hull and compass. The better part of Copernicus was to direct man to a viewpoint whence he should see that the heavens were of like matter with the earth. All this done, the acorn was planted from which the oak of our civilization should spring. The mad quest for gold which followed the discovery of Columbus, the questionings which absorbed the attention of the learned, the indignation excited by the seeming vagaries of a Parcelsus, the fear and trembling lest the strange doctrine of Copernicus should undermine the faith of centuries, were all helps to the germination of the seed-stimuli to thought which urged it on to explore the new fields opened up to its occupation. This given, all that has since followed came out in regular order of development, and need be here considered only in those phases having a special relation to the purpose of our present meeting.

So slow was the growth at first that the sixteenth century may scarcely have recognized the inauguration of a new era. Torricelli and Benedetti were of the third generation after Leonardo, and Galileo, the first to make a substantial advance upon his theory, was born more than a century after him. Only two or three men appeared in a generation who, working alone, could 
make real progress in discovery, and even these could do little in leavening the minds of their fellowmen with the new ideas.

Up to the middle of the seventeenth century an agent which all experience since that time shows to be necessary to the most productive intellectual activity was wanting. This was the attraction of like minds, making suggestions to each other, criticising, comparing and reasoning. This element was introduced by the organization of the Royal Society of London and the Academy of Sciences of Paris.

The members of these two bodies seem like ingenious youth suddenly thrown into a new world of interesting objects, the purposes and relations of which they had to discover. The novelty of the situation is strikingly shown in the questions which occupied the minds of the incipient investigators. One natural result of British maritime enterprise was that the aspirations of the Fellows of the Royal Society were not confined to any continent or hemisphere. Inquiries were sent all the way to Batavia to know "whether there be a hill in Sumatra which burneth continually, and a fountain which runneth pure balsam." The astronomical precision with which it seemed possible that physiological operations might go on was evinced by the inquiry whether the Indians can so prepare that stupefying herb Datura that "they make it lie several days, months, years, according as they will, in a man's body without doing him any harm, and at the end kill him without missing an hour's time." Of this continent one of the inquiries was whether there be a tree in 
Mexico that yields water, wine, vinegar, milk, honey, wax, thread and needles.

Among the problems before the Paris Academy of Sciences those of physiology and biology took a prominent place. The distillation of compounds had long been practiced, and the fact that the more spirituous elements of certain substances were thus separated naturally led to the question whether the essential essences of life might not be discoverable in the same way. In order that all might participate in the experiments, they were conducted in open session of the Academy, thus guarding against the danger of any one member obtaining for his exclusive personal use a possible elixir of life. A wide range of the animal and vegetable kingdom, including cats, dogs and birds of various species, were thus analyzed. The practice of dissection was introduced on a large scale. That of the cadaver of an elephant occupied several sessions, and was of such interest that the monarch himself was a spectator.

To the same epoch with the formation and first work of these two bodies belongs the invention of a mathematical method which in its importance to the advance of exact science may be classed with the invention of the alphabet in its relation to the progress of society at large. The use of algebraic symbols to represent quantities had its origin before the commencement of the new era, and gradually grew into a highly developed form during the first two centuries of that era. But this method could represent quantities only as fixed. It is true that the elasticity inherent in the use of such symbols permitted of their being applied to any and 
every quantity; yet, in any one application, the quantity was considered as fixed and definite. But most of the magnitudes of nature are in a state of continual variation; indeed, since all motion is variation, the latter is a universal characteristic of all phenomena. No serious advance could be made in the application of algebraic language to the expression of physical phenomena until it could be so extended as to express variation in quantities, as well as the quantities themselves. This extension, worked out independently by Newton and Leibnitz, may be classed as the most fruitful of conceptions in exact science. With it the way was opened for the unimpeded and continually accelerated progress of the last two centuries.

The feature of this period which has the closest relation to the purpose of our coming together is the seemingly unending subdivision of knowledge into specialties, many of which are becoming so minute and so isolated that they seem to have no interest for any but their few pursuers. Happily science itself has afforded a corrective for its own tendency in this direction. The careful thinker will see that in these seemingly diverging branches common elements and common principles are coming more and more to light. There is an increasing recognition of methods of research, and of deduction, which are common to large branches, or to the whole of science. We are more and more recognizing the principle that progress in knowledge implies its reduction to more exact forms, and the expression of its ideas in language more or less mathematical. The problem before the organizers of this Congress was, therefore, to bring the sciences 
together, and seek for the unity which we believe underlies their infinite diversity.

The assembling of such a body as now fills this hall was scarcely possible in any preceding generation, and is made possible now only through the agency of science itself. It differs from all preceding international meetings by the universality of its scope, which aims to include the whole of knowledge. It is also unique in that none but leaders have been sought out as members. It is unique in that so many lands have delegated their choicest intellects to carry on its work. They come from the country to which our republic is indebted for a third of its territory, including the ground on which we stand; from the land which has taught us that the most scholarly devotion to the languages and learning of the cloistered past is compatible with leadership in the practical application of modern science to the arts of life; from the island whose language and literature have found a new field and a vigorous growth in this region; from the last seat of the holy Roman Empire; from the country which, remembering a monarch who made an astronomical observation at the Greenwich Observatory, has enthroned science in one of the highest places in its government; from the peninsula so learned that we have invited one of its scholars to come and tell us of our own language; from the land which gave birth to Leonardo, Galileo, Torricelli, Columbus, Volta - what an array of immortal names! - from the little republic of glorious history which, breeding men rugged as its eternal snow-peaks, has yet been the seat of scientific investigation since the day of the Bernoullis; from the land whose heroic 
dwellers did not hesitate to use the ocean itself to protect it against invaders, and which now makes us marvel at the amount of erudition compressed within its little area; from the nation across the Pacific, which, by half a century of unequaled progress in the arts of life, has made an important contribution to evolutionary science through demonstrating the falsity of the theory that the most ancient races are doomed to be left in the rear of the advancing age-in a word, from every great center of intellectual activity on the globe I see before me eminent representatives of that worldadvance in knowledge which we have met to celebrate. May we not confidently hope that the discussions of such an assemblage will prove pregnant of a future for science which shall outshine even its brilliant past.

Gentlemen and scholars all! You do not visit our shores to find great collections in which centuries of humanity have given expression on canvas and in marble to their hopes, fears and aspirations. Nor do you expect institutions and buildings hoary with age. But as you feel the vigor latent in the fresh air of these expansive prairies, which has collected the products of human genius by which we are here surrounded, and, I may add, brought us together; as you study the institutions which we have founded for the benefit, not only of our own people, but of humanity at large; as you meet the men who, in the short space of one century, have transformed this valley from a savage wilderness into what it is today-then may you find compensation for the want of a past like yours by seeing with prophetic eye a future world-power of which this region shall be the seat. If such is to be the 
outcome of the institutions which we are now building up, then may your present visit be a blessing both to your posterity and ours by making that power one for good to all mankind. Your deliberations will help to demonstrate to us and to the world at large that the reign of law must supplant that of brute force in the relations of the nations, just as it has supplanted it in the relations of individuals. You will help to show that the war which science is now waging against the sources of diseases, pain and misery offers an even nobler field for the exercise of heroic qualities than can that of battle. We hope that when, after your all toofleeting sojourn in our midst, you return to your own shores, you will long feel the influence of the new air you have breathed in an infusion of increased vigor in pursuing your varied labors. And if a new impetus is thus given to the great intellectual movement of the past century, resulting not only in promoting the unification of knowledge, but in widening its field through new combinations of effort on the part of its votaries, the projectors, organizers and supporters of this Congress of Arts and Science will be justified of their labors. 


\section{DAY USE \\ RETURN TO DESK FROM WHICH BORROWED LOAN DEPT.}

This book is due on the last date stamped below, or on the date to which renewed.

Renewed books are subject to immediate recall.

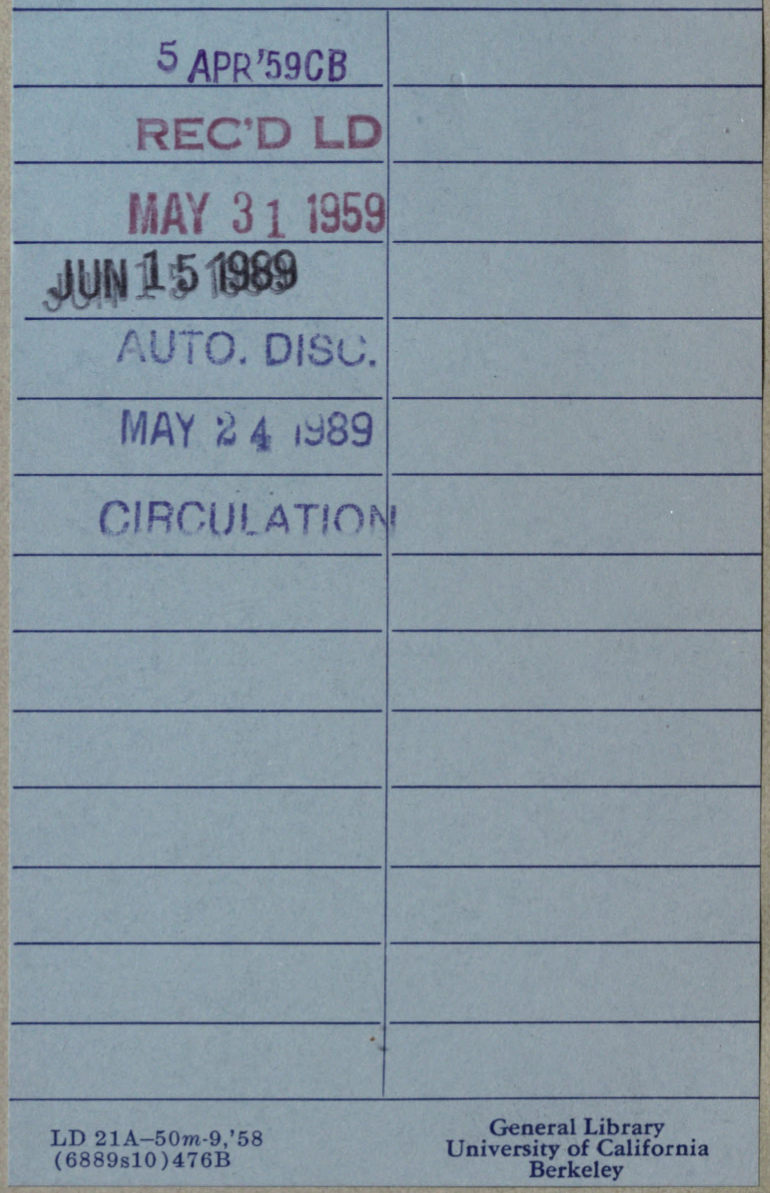




\section{U.C. BERKELEY LIBRARIES

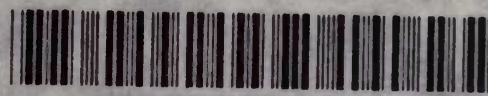 C020913650}

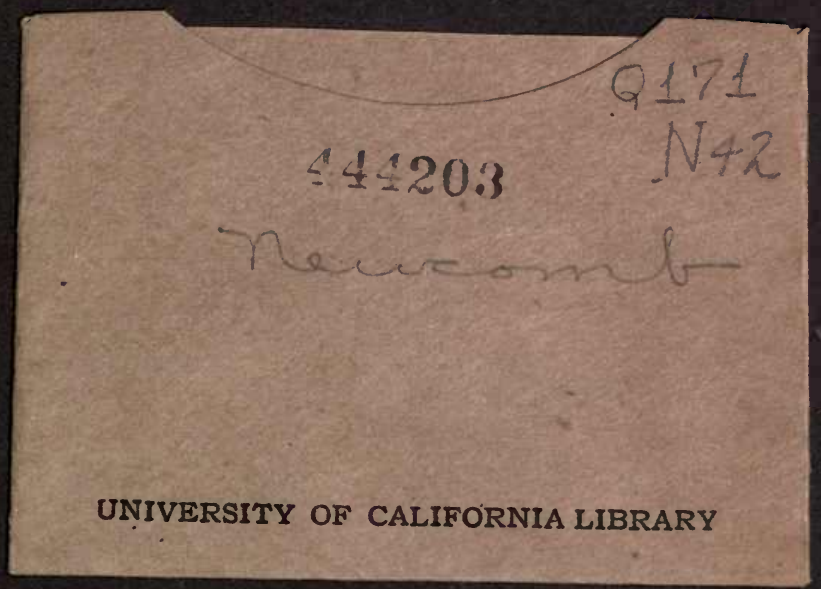


